\title{
Effect of diabetes associated increases in lens optical density on colour discrimination in insulin dependent diabetes
}

\author{
Kevin J Hardy, John H B Scarpello, David H Foster, Jack D Moreland
}

\begin{abstract}
Optical density (OD) of the crystalline lens has been shown in non-diabetics to increase linearly with age over the first five decades and at an increased rate thereafter; in insulin dependent diabetic (IDDM) patients, lens OD increases with age and with duration of diabetes at a rate similar to that in non-diabetics over the age of 60 years. Recently, it has been established that colour discrimination is abnormal in a majority of young patients with uncomplicated IDDM and angiographically normal retinas. Colour discrimination loss was attributed to functional abnormalities in the retina or neural pathways; yet the possibility exists that increases in lens OD may account for part or all of the colour discrimination loss in IDDM. In the present study, colour discrimination was compared in aretinopathic IDDM patients and age-matched controls, and then in a group of aretinopathic IDDM patients individually matched to controls with respect to lens OD. Colour discrimination was significantly worse in diabetic patients than in age-matched controls, and was significantly worse when diabetic patients were compared with controls matched for $O D$. The magnitude of the difference in 100 hue error score between diabetic patients and OD matched controls was, however, considerably less than the difference between diabetic patients and age-matched controls. These data suggest that colour discrimination loss in aretinopathic IDDM patients cannot be explained solely on the basis of diabetes induced increases in lens $O D$, but must involve abnormalities of the retina or its neural connections.
\end{abstract}

(Br f Ophthalmol 1994; 78: 754-756)

Department of Endocrinology and Diabetes, North Staffordshire Royal Infirmary, Princes Road, Stoke-on-Trent K J Hardy

J H B Scarpello

Department of Communication and Neuroscience, Keele University, Keele, Staffs D H Foster

J D Moreland

Correspondence to:

Dr K J Hardy, Department of Endocrine and Metabolic Diseases, Metabolic Unit, Western General Hospita EH4 2XU.

Accepted for publication 26 May 1994 increases with increasing age and with decreasing wavelength of light. ${ }^{12}$ The increased absorption of short wavelength light sometimes causes the lens to appear yellow. Analysis of combined data from psychophysical and physical measurements of lens absorption has shown that in the general population lens OD increases at a constant rate with age until approximately 60 years of age and at a greater rate thereafter. ${ }^{3}$ In diabetes, however, fluorophotometry, ${ }^{4}$ quasielastic light scattering spectroscopy, ${ }^{5}$ Scheimflug photography, ${ }^{6}$ and psychophysical measurements ${ }^{7}$ have all demonstrated an increased rate of lens yellowing. Using Scheimflug photography, Sparrow et $a l^{6}$ demonstrated that even patients with relatively short diabetes duration have lenses of greater OD than their non-diabetic
Optical density (OD) of the crystalline lens counterparts, and that increases in OD are strongly correlated with diabetes duration. ${ }^{6}$ Using psychophysical techniques, Lutze and Bresnick $^{7}$ confirmed accelerated lens yellowing in young insulin-dependent diabetic (IDDM) patients and showed that lens yellowing increased with age and with duration of diabetes at a rate similar to that in non-diabetics older than 60 years. Recently, it has been shown that colour discrimination is abnormal in a majority of young patients with uncomplicated IDDM without retinopathy; it was assumed that these changes in colour discrimination represent functional disturbances in the retina or post-retinal neural pathways; yet the possibility exists that changes in lens OD may explain all or part of this colour discrimination loss. The aim of the present study was to assess the contribution of premature increases in lens OD to colour discrimination loss in young uncomplicated type 1 diabetic patients without retinopathy.

\section{Methods}

SUBJECTS

Thirty eight young patients with uncomplicated IDDM of mean age $26 \cdot 1$ (SD 6.8) years and with mean diabetes duration of $8 \cdot 1(4 \cdot 9)$ years were investigated and compared with 36 age-matched controls. Patients had stable intermediate term blood glucose control with a mean glycated haemoglobin of $10 \cdot 2 \%$ (1.9\%) (Corning method, laboratory reference range $5 \cdot 5-8 \cdot 2 \%)$. Eye examination in the diabetic patients comprised corrected Snellen acuity, tonometry, slit-lamp examination of the lens and anterior chamber, fundus photography, and fluorescein angiography, all of which were normal in every patient. Twenty five of the diabetic patients were then individually matched to non-diabetic controls on the basis of lens OD (appropriate controls could not be found for the other 13 patients). None of the controls were receiving medication, none had a history of diabetes or eye disease, and none was known to have abnormal colour vision. Controls did not have earlier experience of the 100 hue test. The study was approved by the North Staffordshire Hospital ethics committee and all subjects gave written informed consent before study.

\section{MATCHING CONTROLS FOR OPTICAL DENSITY}

Controls of equal OD were matched according to, age by means of the following calculations.

From the Pokorny et $a l^{3}$ model of lens aging, 
the lens optical density $D$ is given in terms of age $A$ (in years) by

$$
D=D_{1}[p+q(A-r)]+D_{2}
$$

where $D_{1}, D_{2}$ are wavelength dependent constants, and $p, q$, and $r$ are age range constants. For the Lutze and Bresnick experiment, ${ }^{7} D_{1}, D_{2}$ represent $O D$ differences at wavelengths 420 and $550 \mathrm{~nm}$ respectively. Thus

$$
D_{1}=0 \cdot 340
$$

and

$$
D_{2}=0 \cdot 300
$$

(see Pokorny et $a l^{3}$ ). From the Pokorny et al constants for young $(\mathrm{Y})$ and old $(\mathrm{O})$ eyes, the corresponding lens ODs are

$$
D_{\mathrm{Y}}=0 \cdot 4224+0 \cdot 0068 \mathrm{~A}
$$

and

$$
D_{\mathrm{O}}=-0 \cdot 5303+0 \cdot 02268 \mathrm{~A}
$$

From equation ( 1 ), the predicted age is

$$
A=\left(D_{\mathrm{Y}}-0 \cdot 4224\right) / 0 \cdot 0068
$$

For a young diabetic patient, the lens OD $B$ is given in terms of diabetes duration $T$ (in years) by

$$
B=D_{\mathrm{Y}}+0.017 T
$$

where the regression line in Figure $3 a$ of the Lutze and Bresnick study ${ }^{7}$ has been constrained to pass through the origin. This differs from the unconstrained expression $\left(B=D_{\mathrm{Y}}+0.0173 T-0.0260\right)$ used by Moreland,' but the effect on the age of the lens equivalent controls is small.

From equations (1)-(4), the lens equivalent normal age $E$ is given by

$$
E=[(0.4224+0 \cdot 0068 A+0.017 T)-0 \cdot 4224] / 0 \cdot 0068
$$

which, after simplification, becomes

$$
E=A+2 \cdot 5 T
$$

Equation (5) is valid for values of $E$ between 20 and 60 years. that

If $E>60$ years, then a similar analysis shows

$$
E=42 \cdot 0+0 \cdot 30 A+0 \cdot 75 T
$$

With the aid of equations (5) and (6), 25 diabetic patients were matched individually to controls whose ages were such that they had equal lens ODs. The acceptable precision of age differences between control and diabetic patients was estimated from a polynomial fit of the data of Verriest $e a^{10}$ in which square root 100 hue error scores were expressed as a function of age. Table 1 shows interpolated values from the polynomial fit, and it can be seen that, for the age range of interest (23-69 years), the most sensitive agedependent region is around 35 years. Here a 1 year age change produces the same percentage change in square root 100 hue error score, namely $2 \cdot 4 \%$, as a 5 year age change at age 50

\begin{tabular}{|c|c|c|c|c|c|}
\hline $\begin{array}{l}\text { Age } \\
\text { (years) }\end{array}$ & $\begin{array}{l}\text { Square root } \\
100 \text { hue } \\
\text { error }\end{array}$ & $\begin{array}{l}\text { Age } \\
\text { (years) }\end{array}$ & $\begin{array}{l}\text { Square root } \\
\text { l00 hue } \\
\text { error }\end{array}$ & $\begin{array}{l}\text { Age } \\
\text { (years) }\end{array}$ & $\begin{array}{l}\text { Square root } \\
100 \text { hue } \\
\text { error }\end{array}$ \\
\hline $\begin{array}{l}15 \\
16 \\
17 \\
18 \\
19 \\
20 \\
21 \\
22 \\
23 \\
24 \\
25 \\
26 \\
27 \\
28 \\
29 \\
30 \\
31 \\
32 \\
33 \\
34\end{array}$ & $\begin{array}{l}7 \cdot 490 \\
7 \cdot 079 \\
6 \cdot 729 \\
6 \cdot 437 \\
6 \cdot 198 \\
6 \cdot 008 \\
5 \cdot 865 \\
5 \cdot 764 \\
5 \cdot 703 \\
5 \cdot 678 \\
5 \cdot 685 \\
5 \cdot 721 \\
5 \cdot 784 \\
5 \cdot 869 \\
5 \cdot 974 \\
6 \cdot 095 \\
6 \cdot 230 \\
6 \cdot 375 \\
6 \cdot 529 \\
6 \cdot 688\end{array}$ & $\begin{array}{l}35 \\
36 \\
37 \\
38 \\
39 \\
40 \\
41 \\
42 \\
43 \\
44 \\
45 \\
46 \\
47 \\
48 \\
49 \\
50 \\
51 \\
52 \\
53 \\
54\end{array}$ & $\begin{array}{l}6 \cdot 849 \\
7 \cdot 011 \\
7 \cdot 171 \\
7 \cdot 328 \\
7 \cdot 479 \\
7 \cdot 623 \\
7 \cdot 759 \\
7 \cdot 885 \\
8 \cdot 001 \\
8 \cdot 107 \\
8 \cdot 202 \\
8 \cdot 287 \\
8 \cdot 361 \\
8 \cdot 425 \\
8 \cdot 480 \\
8 \cdot 528 \\
8 \cdot 569 \\
8 \cdot 606 \\
8 \cdot 639 \\
8 \cdot 672\end{array}$ & $\begin{array}{l}55 \\
56 \\
57 \\
58 \\
59 \\
60 \\
61 \\
62 \\
63 \\
64 \\
65 \\
66 \\
67 \\
68 \\
69 \\
70 \\
71 \\
72 \\
73 \\
74\end{array}$ & $\begin{array}{r}8 \cdot 706 \\
8 \cdot 743 \\
8 \cdot 786 \\
8 \cdot 838 \\
8 \cdot 899 \\
8 \cdot 973 \\
9 \cdot 062 \\
9 \cdot 166 \\
9 \cdot 288 \\
9 \cdot 429 \\
9 \cdot 588 \\
9 \cdot 765 \\
9 \cdot 959 \\
10 \cdot 169 \\
10 \cdot 391 \\
10 \cdot 620 \\
10 \cdot 851 \\
11 \cdot 077 \\
11 \cdot 290 \\
11.477\end{array}$ \\
\hline
\end{tabular}
years. This critical interval of plus or minus $2.4 \%$ in the square root 100 hue error score was used to define the acceptable precision of the difference. Table 2 shows the ages of the 25 diabetic patients and their OD matched controls.
Table 1 Interpolation table from 7 th order weighted polynomial fit (99.996\% fit) of the data of Verriest et $\mathrm{al}^{10}$ on the relation between colour discrimination and age

COLOUR DISCRIMINATION ASSESSMENT

Colour discrimination was assessed with the Farnsworth-Munsell 100 hue test (Kollmorgen Corporation, Baltimore, MD, USA) as described previously. ${ }^{8}$ Briefly, each subject performed the 100 hue test monocularly under a simulated North Sky light (Northlight, Thorn EMI Lighting, London, UK) according to the original instructions." The original Farnsworth scoring convention was also used. ${ }^{1}$ Meter read capillary blood glucose measurements (ExacTech System, Baxter Travenol Laboratories Inc, IL, USA) estimated at -1 hour, -30 minutes, and immediately before and after the 100 hue test were stable in all patients (mean peri-test blood glucose $9 \cdot 7(3 \cdot 8) \mathrm{mmol} \mathrm{l}^{-1}$ (range $5-20 \mathrm{mmol}$

\begin{tabular}{|c|c|c|c|c|}
\hline \multicolumn{3}{|c|}{ Diabetic patients } & \multicolumn{2}{|c|}{ Controls } \\
\hline $\begin{array}{l}\text { Age } \\
\text { (years) }\end{array}$ & $\begin{array}{l}\text { Diabetes } \\
\text { duration } \\
\text { (years) }\end{array}$ & $\begin{array}{l}\text { Square root } \\
100 \text { hue } \\
\text { error }\end{array}$ & $\begin{array}{l}\text { Age } \\
\text { (years) }\end{array}$ & $\begin{array}{l}\text { Square root } \\
\text { lo0 hue } \\
\text { error }\end{array}$ \\
\hline 27 & 9 & $8 \cdot 72$ & 50 & 5.66 \\
\hline 18 & 10 & $9 \cdot 38$ & 43 & 6.00 \\
\hline 39 & 15 & $9 \cdot 17$ & 65 & $12 \cdot 49$ \\
\hline 26 & 4 & 10.95 & 36 & 6.63 \\
\hline 27 & 5 & $15 \cdot 10$ & 40 & $5 \cdot 29$ \\
\hline 33 & 1 & $9 \cdot 38$ & 36 & $6 \cdot 00$ \\
\hline 40 & 5 & 4.90 & 53 & 8.00 \\
\hline 23 & 10 & 8.49 & 48 & $8 \cdot 49$ \\
\hline 27 & 7 & $7 \cdot 75$ & 44 & $5 \cdot 29$ \\
\hline 30 & 13 & 8.94 & 61 & $8 \cdot 25$ \\
\hline 38 & 5 & $6 \cdot 63$ & 51 & $5 \cdot 29$ \\
\hline 33 & 12 & 6.93 & 61 & $7 \cdot 87$ \\
\hline 20 & 4 & $10 \cdot 39$ & 30 & $7 \cdot 48$ \\
\hline 35 & 2 & $9 \cdot 80$ & 40 & $6 \cdot 32$ \\
\hline 19 & 8 & 8.00 & 39 & $4 \cdot 47$ \\
\hline 21 & 4 & $4 \cdot 00$ & 31 & $10 \cdot 00$ \\
\hline 28 & 10 & $16 \cdot 28$ & 53 & $7 \cdot 75$ \\
\hline 18 & 2 & $8 \cdot 72$ & 23 & $5 \cdot 66$ \\
\hline 21 & 13 & $12 \cdot 33$ & 54 & 8.00 \\
\hline 21 & 10 & 10.58 & 46 & $2 \cdot 00$ \\
\hline 18 & 9 & $7 \cdot 75$ & 41 & $2 \cdot 83$ \\
\hline 19 & 8 & 8.49 & 39 & $9 \cdot 17$ \\
\hline 39 & 13 & $10 \cdot 77$ & 63 & $6 \cdot 48$ \\
\hline 21 & 1 & $8 \cdot 25$ & 24 & $4 \cdot 47$ \\
\hline 24 & 0.5 & 5.66 & 25 & $7 \cdot 21$ \\
\hline
\end{tabular}
$\left.1^{-1}\right)$ ). No patient was hypoglycaemic during colour vision assessment.

\section{STATISTICAL METHODS}

All data are expressed as mean (1 SD) unless otherwise stated. 100 Hue error scores are abnormally distributed and were therefore normal-

Table 2 Age and diabetes duration of 25 diabetic patients and 25 controls individually matched for lens optical density from equation (5) or (6) and the tolerance specified in the text 
Table 3 Mean (SE) age and square root 100 hue error score in 38 diabetic patients, 36 age-matched non-diabetic controls, and 25 non-diabetic controls individually matched to diabetic patients on the basis of lens optical density $(O D)$

\begin{tabular}{llll}
\hline & $\begin{array}{l}\text { Diabetic } \\
\text { patients }\end{array}$ & $\begin{array}{l}\text { Age matched } \\
\text { controls }\end{array}$ & $\begin{array}{l}\text { OD matched } \\
\text { controls }\end{array}$ \\
\hline $\begin{array}{l}\text { Mean age (years) } \\
\begin{array}{l}\text { Mean square root } 100 \text { hue } \\
\text { error score }\end{array}\end{array}$ & $\begin{array}{l}26(7) \\
9 \cdot 0(0 \cdot 3)\end{array}$ & $25(4)$ & $44(12) \dagger$ \\
\hline
\end{tabular}

$\mathrm{tp}<0.001$ with respect to diabetic patients.

${ }^{*} \mathrm{p}<0.005$ with respect to diabetic patients.

ised by a square root operation according to the method of Kinnear. ${ }^{12}$ Comparison of 100 hue error scores in diabetic patients and age-matched controls was by an unpaired two tailed Student's $t$ test. Comparison of 100 hue error scores in diabetic patients and individually OD matched controls was by Student's $t$ test for paired comparisons.

\section{Results}

Colour discrimination performance in the diabetic group, age-matched controls, and controls matched for lens OD are shown in Table 3. There was a highly significant difference in colour discrimination ability between diabetic patients and age-matched controls (mean (SE) square root 100 hue error score for diabetic patients $9.0(0.3)$ versus $4.9(0.3)$ in age-matched controls, $\mathrm{p}<<0.001)$. However, there was also a significant difference in colour discrimination ability between diabetic patients and controls matched for lens OD (mean (SE) square root 100 hue error score for diabetic patients $9 \cdot 1(0.6)$ versus $6.7(0.4)$ for lens OD matched controls, $\mathrm{p}<0.005)$. Visual inspection and Fourier analysis ${ }^{13}$ of a polar plot of each patient's 100 hue test result showed no evidence of a specific axis of colour discrimination impairment.

\section{Discussion}

The results of this study suggest that colour discrimination loss in young IDDM patients without retinopathy is the result of changes both in the crystalline lens and in the retina or its neural connections. Despite stable short and intermediate term diabetes control, colour discrimination was highly significantly worse in diabetic patients than in age-matched nondiabetic controls, and was also significantly worse in diabetic patients than in controls matched for lens OD. If increases in lens OD were the sole cause of colour discrimination loss in diabetic patients, matching for OD would have compensated for the loss, but a significant difference between the two groups persisted. Increases in lens OD preferentially affect transmission of short wavelength light (lens yellowing); the lack of a specific axis of colour discrimination impairment in this study suggests a relatively small contribution of increases in lens OD to colour discrimination impairment.

It may be relevant that the magnitude of the difference between the mean square root 100 hue error scores for diabetic patients and OD matched controls $(9 \cdot 1$ versus $6 \cdot 7)$ was considerably less than the difference between diabetic patients and age-matched controls $(9 \cdot 0$ versus 4.9). Expressed another way, there was a significant difference in colour discrimination ability between the two kinds of control groups (mean square root 100 hue error score for agematched controls was $4.9(1.8)$ versus $6.7(2 \cdot 2)$ for OD matched controls, $\mathrm{p}<0.001)$. The OD matched controls, however, were selected on the basis of age-induced changes in lens OD, and were significantly older than age-matched controls (44 (12) years OD matched controls versus 25 (4) years age-matched controls, $\mathrm{p}<0.001$ ). Colour discrimination ability is known to deteriorate with age, although the extent to which this deterioration results from age-related increases in lens OD rather than from reduced cone pathway sensitivity is unclear. Ruddock suggested ${ }^{14}$ that response of the receptor system of the eye remains largely unchanged with age. But, as Weale has pointed out, ${ }^{15}$ the sample on which Ruddock based these observations was small, and Ruddock himself was somewhat guarded in his conclusions about preservation of receptoral function with age. In contrast, spectral sensitivity measurements by Werner and Steele ${ }^{16}$ suggest that all three cone types, or at least one of their post-receptoral pathways, or possibly both receptors and post-receptoral pathways, deteriorate with age.

In summary, the present findings suggest that colour discrimination loss in aretinopathic IDDM patients cannot be explained solely on the basis of diabetes induced increases in lens OD, but must involve abnormalities of the retina or its neural connections or both. The precise extent to which diabetes induced premature increases in lens OD contribute to colour discrimination loss in IDDM remains to be determined.

KJH was supported by a grant from Scotia Pharmaceuticals Ltd Woodbridge Meadows, Guildford, Surrey. The help of Sister Woodbridge Meadows, Guildford, Surrey. The help of Sister Sandra Sheppard in the rec
this study was appreciated.

l Said FS, Weale RA. The variation with age of the spectral transmissivity of the living human crystalline lens. Gerontologia 1959; 3: 213-31.

2 Werner JS, Wooten BR. Age changes in ocular media density and consequences for colour vision. In: Verriest G, ed. Colour vision deficiencies V. Bristol: Adam Hilger, 1980 355-9.

3 Pokorny J, Smith VC, Lutze M. Aging of the human lens. Applied Optics 1987; 26: 1437-40

4 Van-Best JA, Vrij L, Oosterhuis JA. Lens transmission of blue-green light in diabetic patients as measured by autofluorophotometry. Invest Ophthalmol Vis Sci 1985; 26 : $532-6$.

5 Bursell S, Baker RS, Weiss JN, Haughton JF, Rand LI. Clinical photon correlation spectroscopy evaluation of human diabetic lenses. Exp Eye Res 1989; 49: 241-58.

6 Sparrow JM, Bron AJ, Phelps-Brown NA, Neil HAW. Biometry of the crystalline lens in early-onset diabetes. Biometry of the crystalline lens in

7 Lutze M, Bresnick GH. Lenses of diabetic patients 'yellow' at an accelerated rate similar to older normals. Invest Ophthalmol Vis Sci 1991; 32: 194-9.

8 Hardy KJ, Lipton J, Foster DH, Scarpello JHB. Detection of colour vision abnormalities in uncomplicated type 1 diabetic patients with angiographically normal retinas. $\mathrm{Br} \mathcal{J}$ Ophthalmol 1992; 76: 461-4.

9 Moreland JD. Lens equivalent age-controls for diabetics. Invest Ophthalmol Vis Sci 1993; 34: 281-2.

10 Verriest G, Van Laethem J, Uvijls A. A new assessment of the normal ranges of the Farnsworth-Munsell 100-Hue test normal ranges of the Farnsworth-Munsell
scores. Am $\mathcal{F}$ Ophthalmol 1982; 93: 635-42.

11 Farnsworth D. The Farnsworth-M unsell 100-Hue Test Manual. Baltimore: Munsell Colour Company, 1957.

12 Kinnear PR. Proposals for scoring and assessing the 100-Hue test. Vision Res 1970; 10: 423-33.

13 Allan D. Fourier analysis and the Farnsworth-Munsell 100Hue test. Ophthalmol Physiol Opt 1985; 5: 337-42.

14 Ruddock KH. The effect of age upon colour vision - II. Changes with age in transmission of the optic media. Vision Res 1965: 5: 47-58.

15 Weale RA. Colour vision and age. In: Verriest G, ed. Colour vision deficiencies VIII. Dordrecht, The Netherlands: Martinus Nijhoff/Dr W Junk Publishers, 1987: 85-98.

16 Werner JS, Steele VG. Sensitivity of human foveal color mechanisms throughout the life span. F Opt Soc Am A 1988; 5: 2122-30. 